\title{
Urdimento
}

\section{PROCESSOS DE TRANS - FORMA - CÃO NOS ATOS CRIATIVOS: UMA POÉTICA NA TROCA DE SINGULARIDADES}

\author{
Alexandre Mate ${ }^{1}$
}

\section{Resumo}

A reflexão aqui desenvolvida acerca do processo criativo apresenta algumas especulações quanto: ao conceito da forma; a algumas distinções entre símbolo e alegoria; à importância dos acasos na criação artística; ao homem ser um ressignificador (homo symbolicum e homo estheticus); à sofisticação pressuposta pela forma teatral; ao fato de a poética ocorrer no encontro entre artistas e público, na junção de múltiplas singularidades que concretizam uma nova e irrepetível relação.

Palavras-chave: processo de criação e teatro, símbolo/alegoria/forma na criação, teatro como processo criativo.

\begin{abstract}
The present study on the creative process develops some speculations: on the concept of form; on a few distinctions between symbol and allegory; on the significance of hazard during artistic creation; on man as a re-signifier (homo symbolicum e homo estheticus); on the presupposed sophistication of theatrical form; on the occurrence of poetics at the encounter between public and artists, at the joint of multiple singularities which realize new and singular rapports.
\end{abstract}

Keywords: creative process and theater, symbol/allegory/way of creation, theater as a creative process.

[...] quem sabe se o melhor das obras de arte não surge do imperfeito domínio do material como uma primícia, uma aparição súbita, que se desfaz assim que se torna tecnicamente disponivel. Theodor ADORNO. Palavras e sinais.

Segundo Faiga Ostrower, em Criatividade e processos de criação (1984), o homem cria não porque quer, mas porque necessita. Em sendo intrínseca à existência a necessidade de criação estética, afirma ainda a autora que nada existe que não seja forma. Circundado e envolvido por formas (materiais ou imateriais, artísticas ou não), o homem precisa, também, dar forma às suas

\footnotetext{
IProfessor do Instituto de Artes da Universidade Estadual Paulista Julio de Mesquita

Filho - Campus São

Paulo. Doutorado em História Social

- FFLCH/USP.

Pesquisador de teatro e do Núcleo Nacional de Teatro de Rua. Autor do livro Buraco d'Oráculo: uma trupe paulistana de jogatores desfraldando espetáculos pelos espaços públicos da cidade. São Paulo: publicação do Grupo, 2009. Trinta anos da Cooperativa Paulista de Teatro: uma história de tantos (ou mais quantos, e sempre juntos) trabalhadores fazedores de teatro. São Paulo: IMESP, 2009 (no prelo).
} 


\section{Urdimento}

2Disponível em www.jayrus.art.br/ Apostilas/ LiteraturaBrasileira/ VanguardasPoeticas/ Jose Lino Grunewald poesia.htm Acesso em $21 / 07 / 2009$, às $12 \mathrm{~h} 01$. necessidades, repeti-las ou romper com cadeias delas e a ele impostas pelos mais variados modos e expedientes. Por esta senda, no indivíduo confrontamse, ainda segundo Ostrower “(...) dois pólos de uma mesma relação: a sua criatividade que representa as potencialidades de um ser único, e sua criação que será a realização dessas potencialidades já dentro do quadro de determinada cultura." (OSTROWER, 1984, p. 5)

Toda criação pressupõe a ativação e realização de um processo complexo que compreende o trânsito entre o imaginar e a sua operacionalização em forma, ou por meio de formas. Deflagrado pelo imaginar - uma ideia, uma aparição (epifânica ou não), uma prefiguração -, a trilha criativa pressupõe a transformação dos signos imaginados em símbolos e alegorias que precisam se materializar, os quais, em seu deslocamento e errância (individual/ coletiva), abriguem o signo ou o conjunto inicial a partir do qual ele se reformou ou se conformou.

A palavra-conceito remete a muitos artistas e teóricos. Deles todos, para descortinar terrenos e territórios, evocar uma obra de José Lino Grünewald, sem nome, cujo assunto, imbricado à forma, pode ser surpreendente.

$$
\begin{gathered}
\text { forma } \\
\text { reforma } \\
\text { disforma } \\
\text { transforma } \\
\text { conforma } \\
\text { informa } \\
\text { forma }
\end{gathered}
$$

Parafraseando Carlos Drummond de Andrade, em Procura da poesia: "O que pensas e sentes, isso ainda não é poesia." A criação, enquanto processo, pressupõe a transformação do pensado em matéria, em linguagem (ou forma) sígnica: visual, pictórica, sonora, corporal. Reiterando: o sonhado (e internalizado apenas no ser) não basta, é preciso transformá-lo em fenômeno comunicacional, em relação entre sujeitos distintos interrelacionados pela obra. Novamente com Drummond, em outro momento do já citado poema: "Penetra surdamente no reino das palavras [que são signos]./ Lá estão os poemas [formas em potência] que esperam ser escritos./ Estão paralisados, mas não há desespero,/ há calma e frescura na superfície intata./ Ei-los sós e mudos, em estado de dicionário." (DRUMMOND de ANDRADE, 1973, p. 138-9).

Com relação ao conceito de signo, símbolo e alegoria transito aqui, fundamentalmente, com as reflexões do filólogo Mikhail Bakhtin (1992), para quem todo signo é histórico e ideológico. O que se pensa, se manifesta, 


\section{Urdimento}

se atribui, se representa, se comunica... é mediado por signos criados pelos homens ao longo da História. No concernente, ainda, às questões sígnicas, apesar de haver algumas diferenças, é bom apresentar algumas considerações de Arnold Hauser (s/d) segundo as quais o símbolo representaria a expressão indireta de um significado impossível de ser dado diretamente, posto sua natureza ser próxima ao indefinível e ao inesgotável.

A arte e as relações humanas desenvolvem-se por intermédio dos símbolos; entretanto, durante o movimento Simbolista francês, ocorrido na França, em fins do século XIX, o trabalho com a imaginação simbólica foi elevada ao paroxismo. Para Charles Baudelaire, no poema Correspondências a natureza era " $[\ldots]$ um templo em que vivas pilastras/ deixam sair às vezes obscuras palavras;/ o homem a percorre através de florestas de símbolos/ que o observam com olhares familiares.” (BAUDELAIRE, 1995, p. 12). Para seu contemporâneo Stéphane Mallarmé (um dos chamados "três reis magos da poética moderna”) a alegoria era concebida como tradução de uma idéia abstrata apresentada por meio de uma imagem concreta. Assim, segundo o poeta, ao se descobrir a idéia contida por “detrás” da alegoria poder-se-ia lê-la e traduzi-la, posto que a traduzibilidade - diferentemente do símbolo - seria intrínseca à sua constituição. Ainda segundo o conceito de alegoria, afirma Antonio Candido (1987): "Considero alegórico o modo que pressupõe a tradução da linguagem figurada por meio de chaves uniformes, conscientemente definidas pelo autor e referidas a um sistema ideológico. Uma vez traduzido, o texto se lê como um segundo texto, sob o primeiro, e se torna tão claro quanto ele. Está visto portanto, que o deciframento do código é altamente convencional, em relação a outros modos de ocultação de sentido, como o simbólico”?

Em oposição à alegoria, o símbolo reuniria a idéia e a imagem resultada em uma unidade indivisível. Assim, a transformação da imagem arrastaria consigo a metamorfose da idéia, na medida em que o conteúdo de um símbolo não poderia ser traduzido de outro modo. Dentre os vários textos que discutem o símbolo, nessa perspectiva, Hegel (s/d, p. 16) afirma:

O símbolo é algo de exterior, um dado direto e que diretamente se dirige à nossa intuição: todavia, este dado não pode ser considerado e aceite tal como existe realmente, para si mesmo, mas num sentido muito mais vasto e geral. É, assim, preciso distinguir no símbolo o sentido e a expressão. Aquele refere-se a uma representação ou um objeto qualquer que seja o seu conteúdo; esta constitui uma existência sensível ou uma imagem qualquer.

Março $2009-\mathrm{N}^{\circ} 12$

Processos de trans - forma - ção nos atos criativos... Alexandre Mate
${ }^{3}$ CANDIDO, Antonio.

Educação pela noite.

São Paulo: Ática, 1987, p. 85.

. 


\section{Urdimento}

Antes de tudo, o símbolo é um sinal. Mas na sua simples presença, o laço que existe entre o sentido e a expressão é puramente arbitrário. Esta expressão que aqui temos, esta imagem, esta coisa sensivel representa tão pouco por si mesma que desperta em nós a idéia de um conteúdo que lhe é completamente alheio, com o qual ela não tem, para falar com propriedade, nada de comum. (...) A arte implica, pelo contrário, uma relação, um parentesco, uma interpenetração concreta de significação e de forma.

Em sendo o artista um criador de símbolos cuja natureza manifestatória fundamenta-se em um permanente processo de troca [simbólica], o que dele emana intenta para se legitimar, enquanto fenômeno, o deslocamento absolutamente necessário no sentido da busca para a formalização da coisaideia (enquanto signo ou sinal). Michel de Certeau (1994) sobretudo em $A$ invenção do cotidiano, afirma que a andança ou o caminhar - em qualquer uma de suas possibilidades de realização - expressam a falta de lugar. Concebido como errância permanente, a materialidade do ato criativo - a partir do ausente à procura de um próprio - converte permanentemente o não-lugar em espaço praticado, em espaço de concretude do sonho, seja ele inalcançável, alcançado, vislumbrado...

O homem recebe pela cultura um caudal de signos fixados, definidos, ideológicos, mas, por necessidade de criar, ressignifica-os em partilha virtual ou vislumbrando uma partilha real. Michel de Certeau, na obra já citada, cria o conceito de re-employ (reutilização). Desse modo, ninguém, por mais alienada que possa parecer sua atitude, deixa de recriar o recebido, inclusive os signos artísticos.

A transformação da página em branco do escritor (hoje, basicamente, substituída pela tela vazia do computador); a outra tela sem qualquer "mácula", traço ou risco do pintor; o bloco de pedra ou a resina informes para o escultor; o palco (ou espaço) vazio do artista ligado às artes da representação; as "palavras que esplendem na curva da noite" "palavras buscando canal" para o poeta (mais uma vez parafraseando Drummond) intentam a errância do artista por entre os caminhos da invenção, da criação, da imaginação, da troca...

O resultado dos processos de criação - a partir dos valores, da cultura, de contextos amplos e restritos, compromissos e filiações estético-políticas... - materializa e potencializa os sentidos, o trânsito com as metáforas, com o caráter polissêmico da arte... Nessa perspectiva, o processo criativo potencializa e harmoniza a necessidade e a errância do homo symbolicum - contemplando o homo sapiens, o homo faber e o homo ludens - até o "tradutor de polissemias" homo estheticus. Este último, mistura (in)orgânica dos anteriores, processa e 


\section{Urdimento}

reinventa para comunicar-se, ainda que não seja de todo entendido. Aliás, entender, por sua dialética intrínseca, pressupõe um afastar-se, para enxergar melhor, a partir de novos ângulos, desopacizadamente. O processo criativo, portanto, instaura cabal e formalmente novos modos de ver. ${ }^{4}$

O processo criativo pressupõe, além da capacidade de ver, o desenvolvimento e ampliação da percepção de todo tipo de intercambiamento possível entre o conceber, o produzir, o colocar em circulação e a recepção da obra. Mesmo que não exista uma apreensão total de cada etapa percorrida pelo criador, todo sujeito se faz na História, por meio da qual recebe, apreende e modifica, permanentemente, a si mesmo e aos outros interrelacionalmente. No concernente à arte propor mudanças, tanto na mentalidade quanto no comportamento, não são poucos os teóricos que pensam a arte como uma potência (tantas vezes vulcânica) que intenta a transformação e a mudança. Do conjunto absolutamente significativo de reflexões de Mario Pedrosa, dois textos de pequena extensão, são alegoricamente significativos nesse particular: Crianças na Petite Galerie e Frade cético, crianças geniais. ${ }^{5}$

À luz do exposto, do mesmo modo que alguns critérios apriorísticos deflagram e norteiam uma trajetória de andança, é fundamental que nesse caminhar se esteja atento e aberto às potências das descobertas e dos achados que vão se dando no sentido da construção, individual ou coletiva, do objeto estético. Reformuladamente, se no processo de criação, a ideia tem certa (i)materialidade ao nascer, no entrechoque de sua realização signica a materialidade ocorre potencializada pelo acaso. No acaso dá-se aquilo que pode ser nomeado como práxis vital. Intrínseco ao processo criativo não fechado, mas permeável ao acolhimento das improvisações em percurso, a manifestação da práxis vital é estimulada, buscada e mesmo provocada nas artes coletivas, como a teatral.

Ainda com relação à prática da práxis vital, nos processos de ensaio, independentemente do resultado final buscado, trata-se de um mecanismo que concerne ao processo, mas cujo procedimento permanece apenas nas obras performáticas ou populares. Acresça-se a isso, ainda, que a obra com partitura aberta e repleta de interstícios preenchíveis em processo de troca explícita ou absolutamente fechada, durante sua exibição (compreendendo o fenômeno teatral), que é o espetáculo, compreende sempre imponderabilidades.

Intrínseco ao processo de criação, certa imponderabilidade é necessária e inevitável. O não conseguir abarcar e organizar o ato criativo cientificamente - donde sua distinção àqueles do cientificismo - implica o trânsito com o poético. Nesse trânsito, a invenção - e a não subsunção do artista aos normativismos, às modas, aos "diz que”, ao simulacro - caracteriza-

\footnotetext{
${ }^{4}$ Expressão cunhada por John BERGER. Acerca do autor, dentre outros,

cf. Modos de ver.

Barcelona: Editorial Gustavo Gili, S.A., s/d.
}

${ }^{5}$ PEDROSA,Mario. Dos murais de Portinari aos espaços de Brasília.

São Paulo:

Perspectiva, respectivamente, p. $71 ;$ p. 75 . 


\section{Urdimento}

${ }^{6}$ FISCHER, Ernst. A função da arte. In: A necessidade da arte. Rio de Janeiro: Zahar Editores, 1980, p.14. se em uma das únicas probabilidades do não arrebatamento da aura - de que fala Benjamin ( $A$ obra de arte na época de sua reprodutibilidade técnica) -, e que se coloca no lugar do original... Segundo Ernst Fischer (1981), ao criar o artista precisa também

(...) dominar, controlar e transformar a experiência em memória, a memória em expressão, a matéria em forma. A emoção para um artista não é tudo; ele precisa também saber tratá-la, transmiti-la, precisa conhecer as regras, técnicas, recursos, formas e convenções com que a natureza - esta provocadora - pode ser dominada e sujeitada à concentração da arte. A paixão que consome o diletante serve ao verdadeiro artista; o artista não é possuído pela besta-fera, mas doma-a.

A tensão e a contradição dialética são inerentes à arte; a arte não só precisa derivar de uma intensa experiência da realidade como precisa ser construída, precisa tomar forma através da objetividade. ${ }^{6}$

Em teatro, que é um trabalho coletivo por excelência, para criar (ou dar forma a) um espetáculo, performance ou exercício, em qualquer etapa da trajetória compreendida pelo processo de criação, é preciso estar atento ao que é construído pelo conjunto de criadores. Na convergência das singularidades, permeada por todo tipo de imprevistos, ocorre o domínio da própria realidade, que se reconforma: parida e alimentada no coletivo. De cada "máquina de imaginância", as ideias individuais e coletivas, materializam-se na insustentável leve-aspereza do grupo e ganha no espetáculo sua função fenomênica. Cada dia, querendo transformar-se em obra - repetido e ensaiado tantas vezes -, o espetáculo ganha novas tessituras, dissonâncias, imprevisibilidades e a ele se atribui múltiplos e diferenciados sentidos pelo conjunto de espectadores. Assim, a poética do processo criativo em teatro realiza-se no e durante cada espetáculo. Poética da efemeridade e do não repetível. Espécie de poética do "não-traduzível". Tradução (do latim translatio), palavra desafiante, cujas raízes semânticas compreendem também traição e difamação (do inglês traduction) e aproximase, ainda, das de tradição.

Na perspectiva defendida por Fayga Ostrower, e aqui já apontada, o ato da criação - que compreende intuição, percepção e pressupõe o estabelecimento de nexo intrínseco entre o sentir e o entender - corresponde a um formar e a dar forma a alguma coisa (os signos). Forma é a expressão resultante e materializada, por intermédio da unidade dialética - repleta de tantas contradições -, entre aquele que cria e o criado. "Na mesma ordem de 
pensamento, entendemos o fazer e o configurar do homem como atuações de caráter simbólico. Toda forma é forma de comunicação ao mesmo tempo em que forma de realização.” (OSTROWER, 1984, p. 5)

Instaurar um fenômeno de comunicação e de troca, decorrente da junção de diversos processos de criação individuais que se agrupam, por intermédio da forma compreendida pelo espetáculo teatral, demanda, sobretudo do criador, entender as maneiras pelas quais o conhecimento possa ser construído e partilhado em sua dimensão fenomênica. Na criação artística, mas não exclusivamente nela, o sujeito relaciona-se com outros sujeitos e com o objeto a ser transformado. Na linguagem teatral o criado, decorrente de procedimentos para contornar os embates, concerne à busca pela melhor forma, e este é repleto de densos processos de pesquisa, que não se conclui jamais...

Mas o que vem a ser um espetáculo teatral?

Ele tem matéria porque feito por atores, que tantas vezes fingem ser o que não são; é iluminado de modo a buscar e evidenciar efeitos plásticos, emocionais e psicológicos; ganha inserções musicais para instaurar climas emocionais, de expectativa, para chamar a atenção de contextos históricos; conta uma história repleta de iscas para "prender" o espectador, levá-lo a formular hipóteses, tornálo cúmplice... A sofisticação e complexidade da obra teatral - cujo resultado é sempre inconcluso (posto que o espetáculo é sempre novo a cada dia) -, dentre outras, pretende transportar emocionalmente, instigar racionalmente, distender comicamente. O espetáculo criaria uma espécie de fratura, no tempo e no espaço, na vida cotidiana. Por meio desse "aprisionamento libertatório" (entra na obra ou deixa arrastar-se por ele quem quer), seu principal propósito talvez fosse falar diretamente ao espírito racional, sensível. Assim como um texto provocador, o espetáculo pode despertar sentimentos dos mais diversos matizes e rigorosamente repleto de antagonismos.

Elaborar uma forma sofisticada, complexa e passível de tantas entradas interpretativas requer certa epistemologia. Caio Prado Júnior, referindo-se às linhas epistemológicas, em Dialética do conhecimento (1980) desenvolve algumas reflexões, aqui apresentadas de modo esquemático, vislumbrando essencialmente uma apreensão didática.

- O empirismo ou positivo lógico:

\begin{tabular}{|l|l|}
\hline A prática condiciona o pensamento & $\begin{array}{l}\text { Pelo fato de o conhecimento, de } \\
\text { e este dirige a prática. }\end{array}$ \\
& $\begin{array}{l}\text { ceutro modo, o observador transforma o } \\
\text { conhecimento em realidade. }\end{array}$ \\
\hline
\end{tabular}




\section{Urdimento}

- O idealismo:

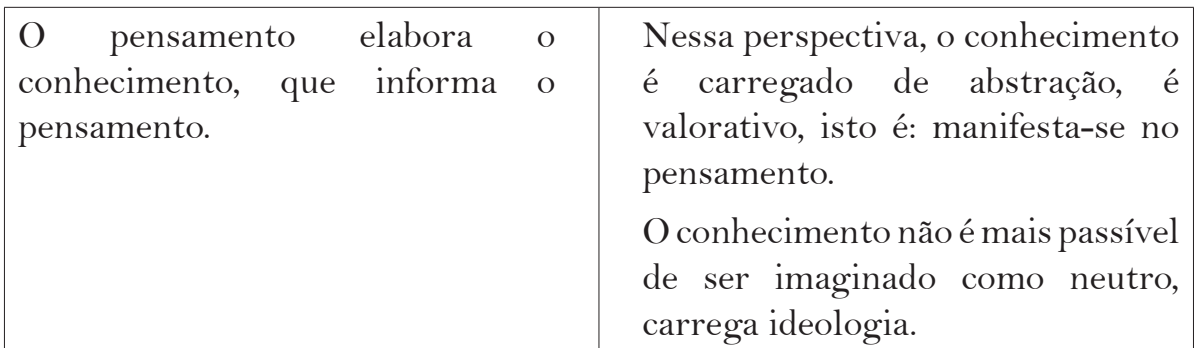

- O dialético (práxis):

A prática condiciona o pensamento, que elabora o conhecimento, que informa o pensamento que dirige a prática.
Nessa proposição, a prática é concebida como ponto de partida e de chegada da construção do conhecimento.

Por sua natureza (junção de tantas outras linguagens para criação do espetáculo) e "realidade" (apresentação de uma obra, com certo estatuto de verdade e de substituição da vida), a criação de um espetáculo teatral pressupõe, na condição de processo, certa epistemologia. Portanto, o poético relaciona-se grandemente com os procedimentos adotados, que tendem a dar suporte, não apenas material, à obra. Processos e procedimentos não sendo abstrações são escolhidos e utilizados pelo conjunto que se organiza para a criação da obra.

De modo bastante grosseiro, dentre tantas outras possibilidades, a adoção de certa epistemologia pode estar rigorosamente plantada em interesses comerciais; outra na tentativa de, por meio do simulacro e de tratamento ilusionista, intentar primordial e essencialmente a identificação emocional; uma última, em intentar a capacidade crítica e, por meio desta, plantar necessidades de entender as relações que regem o "outro mundo”: aquele para além da fratura proposta pela forma ficcional. Em outro contexto, refletindo acerca das interrelações da história e da memória,

${ }^{7}$ MONTENEGRO,

Antonio Torres.

"Memória e história", In: MARTINS, Angela Maria et alii. (coord.). Revista Idéias - 0 tempo e o cotidiano na história. São Paulo: FDE. Diretoria Técnica, 1988, p.10. afirma Antonio Torres Montenegro:

Na tensão da necessidade de inventar outros lugares, sendas, veredas, é que se criam formas de resistência, instituindo imaginários capazes de estabelecer e desenvolver as potencialidades contidas nos limites do engendramento dos desejos não-permitidos; é no próprio labirinto da modernidade aprisionada que se busca tecer os fios, resgatar outras formas de esculpir a realidade que se presentifica cotidianamente. $^{7}$ 


\section{Urdimento}

Recentemente, participando de um processo de discussão acerca de um determinado espetáculo, a diretora da obra, convencida de certos procedimentos (bastante difundidos entre tantos criadores), afirma: "Quando eu crio, me tranco na sala de ensaio, me isolo do mundo real. O mundo exterior se apequena, deixa de existir... No processo de criação não importa a matéria de que sou feita. Importa apenas aquilo que se cria na sala de ensaio. Para criar é preciso isolar-se da vida, da realidade!" Evidentemente, teses dessa natureza plantam-se e são defendidas por muitos. Acreditam estes que ao "apartar-se" do mundo este já não está presentificado dentro do ser. Perpassa por tal estado de alienação ideológica certa apologia àquilo que tantos afirmam ser um abstrato "estado puro da criação". Espécie de encontrar-se ao fugir de si (alusão a poema Autopsicografia de Fernando Pessoa), a criação, como fratura do real, assenta-se sobretudo no conceito de genialidade e alimenta-se de certo estado autista.

O poético na criação, penso, é exatamente a consciência de que por meio também da arte é possível interferir no mundo, reiventando-o. Pelos escaninhos de uma tal concepção, a obra que sai da vida, volta a ela estetizada; portanto, no caso da linguagem teatral, a obra é apenas ponto de partida de um processo repleto de tantos imprevistos...

À luz do exposto, e por absolutamente nada estar apartado do chão da história, o estético pressupõe uma escolha, também, de natureza epistemológicopolítica. Por meio das mediações que a arte propõe e dos processos adotados em sua construtura e partilha, pode-se escolher o modo como se pensa o poético e como este deva se expandir pelo mundo a partir das escolhas que se fez.

Para terminar, quando se vê tudo o que está por aí, sobretudo na Universidade, aninho-me no universo abissal de Clarice Lispector, tão repleto de múltiplos sentidos. Alimento-me, então de formas como:

Acontece que eu achava que nada mais tinha jeito. Então vi um anúncio de uma água de colônia da Coty, chamada Imprevisto. $O$ perfume é barato. Mas me serviu para me lembrar que o inesperado bom também acontece. E sempre que estou desanimada, ponho em mim o Imprevisto. Me dá sorte.

\section{Referências bibliográficas}

ANDRADE, Carlos Drummond. Poesia completa e prosa - volume único. Rio de Janeiro: Companhia José Aguilar Editora, 1973.

BAUDELAIRE, Charles. As flores do mal. São Paulo: Círculo do Livro, 1995.

BERGER, John. Modos de ver. Barcelona: Editorial Gustavo Gili, S.A., s/d.

${ }^{8}$ LISPECTOR, Clarice. Carta para Olga Borelli. Rio de Janeiro, 11 de dezembro de 1970. 


\section{Urdimento}

CANDIDO, Antonio. Educação pela noite. São Paulo: Ática, 1987.

CERTEAU, Michel de. A invenção do cotidiano: 1. artes do fazer. 2 a ed. Petrópolis: Vozes, 1996.

BAKHTIN, Mikhail. Marxismo e filosofia da linguagem. 6aed. São Paulo: Hucitec, 1992.

FISCHER, Ernst. A necessidade da arte. $8^{\mathrm{a}}$ ed. Rio de Janeiro: Zahar Editores, 1981.

HAUSER, Arnold. História social da literatura e das artes. São Paulo: Mestre Jou, s/d, 2v.

HEGEL, Georg W.F. Estética: a arte simbólica. Lisboa: Guimarães Editores, s/d.

MONTENEGRO, Antonio Torres. "Memória e história", In: MARTINS, Angela Maria et alii. (coord.). Revista Idéias - O tempo e o cotidiano na história. São Paulo: FDE. Diretoria Técnica, 1988.

OSTROWER, Fayga. Criatividade e processos de criação. Petrópolis: Vozes, 1984.

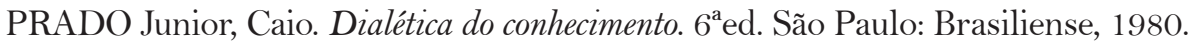

